\title{
Identifikasi Sarana dan Prasarana Sebagai Proses Pengembangan Wilayah Pesisir Barat Kota Tarakan
}

\author{
Eko Prihartanto \\ Program Studi Teknik Sipil, FT UBT, Tarakan \\ Email: eqho.prihartanto@gmail.com
}

Received 30 April 2020; Reviewed 31 Mei 2020; Accepted 29 Juni 2020

Journal Homepage: http://jurnal.borneo.ac.id/index.php/borneoengineering

DOI: https://doi.org/10.35334/be.v4i1.1390

\begin{abstract}
The availability of infrastructure is considered a top priority for the development of coastal areas. Completeness of infrastructure in an area will bring investment from outside into the area. The availability of infrastructure also has a backward relationship that is higher than the relationship in the future which means the availability of infrastructure is more able to encourage the growth of the upstream sector compared to the downstream sector so that infrastructure has an important role in the economic development of coastal areas such as Coastal Selumit Pantai. The method used is a Scalogram Analysis used to see an overview of the level of development of an area administratively using the completeness of facilities and infrastructure (infrastructure) in the region. questionnaire and interview to collect data, with resident respondents in Selumit Pantai village.The results obtained are categories that are included in the hierarchy of the availability of facilities and infrastructure such as There are three hierarchies in Selumit Pantai Village based on a scalogram analysis in which the $R T(R T)$ reviewed is $R T 17,18,19,21$, and 28 covering the hierarchy 3 with low development area.
\end{abstract}

Keywords: Area, Coastal, Infrastructure.

\begin{abstract}
Abstrak
Ketersediaan infrastruktur dianggap sebagai prioritas utama pengembangan kawasan pesisir. Kelengkapan infrastruktur disuatu wilayah akan membawa investasi dari luar masuk ke dalam wilayah tersebut. Ketersediaan infrastruktur juga memiliki keterkaitan kebelakang yang lebih tinggi dari pada keterkaitan kedepannya yang berarti ketersediaan infrastruktur lebih mampu mendorong pertumbuhan sector hulu dibandingkan dengan sector hilir sehingga infrsatruktur mempunyai peranan yang penting dalam perkembangan ekonomi wilayah pesisir seperti Selumit Pantai. Metode yang digunakan adalah Analisis Skalogram digunakan untuk melihat gambaran tingkat perkembangan suatu wilayah secara administratif dengan menggunakan kelengkapan sarana dan prasarana (infrastruktur) di wilayah tersebut. kuesioner dan wawancara untuk mengumpulkan data, dengan responden warga di Kelurahan Selumit pantai.. Hasil yang diperoleh adalah kategori yang masuk dalam hirarki atas ketersediaan sarana dan prasarana seperti Terdapat tiga hirarki di Kelurahan Selumit Pantai berdasarkan analisis skalogram dimana Rukun Tetangga (RT) yang ditinjau yaitu RT 17, 18, 19, 21, dan 28 mencakup ke hirarki 3 dengan pengembangan wilayah yang rendah.
\end{abstract}

Kata kunci: Infrastruktur, Kawasan, Pesisir 


\section{Pendahuluan}

Selumit Pantai adalah salah satu kelurahan di Kecamatan Tarakan Tengah, Kota Tarakan, Provinsi Kalimantan Utara, Indonesia. Selumit pantai ini merupakan salah satu wilayah pesisir yang ada di kota Tarakan. Wilayah pesisir merupakan wilayah yang sangat penting bagi kehidupan manusia. Pada wilayah ini terdapat begitu banyak sumberdaya alam yang sudah seharusnya dilindungi dan dikelola dengan baik. Pada wilayah ini pula kehidupan manusia banyak digantungkan. Diperkirakan bahwa sekitar 50-70\% penduduk dunia tinggal di daerah pesisir (Edgreen dalam Kay dan Alder, 1999) dan memanfaatkan sumberdaya alam yang dimilikinya.

Konsentrasi penduduk di wilayah pesisir Selumit Pantai menyebabkan perkembangan wilayah pesisir lebih maju dibandingkan wilayah pedalaman. Sehingga perkembangan ini dilihat dari tingkat perkembangan wilayah pesisir Selumit Pantai berdasarkan kelengkapan infrastruktur wilayah. Perkembangan wilayah merupakan program yang menyeluruh dan terpadu dari semua kegiatan dengan memperhitungkan sumber daya yang ada dan kontribusinya pada pembangunan di wilayah pesisir tersebut. Penelitian sebelumnya oleh Hendra (2017) dengan objek kawasan kumuh di Kelurahan Selumit Pantai yang berfokus pada variabel indikator pembangunan infrastruktur jalan terdiri dari: peningkatan kualitas jalan, pelebaran jalan, pembangunan jalan baru, pembangunan jembatan, terbukanya akses jalan sedangkan variabel indicator penataan kawasan kumuh terdiri dari: kondisi bangunan gedung, kondisi jalan lingkungan, kondisi penyediaan air minum, kondisi drainase linkungan, kondisi pengelolaan air limbah, kondisi pengelolaan persampahan, kondisi proteksi kebakaran.

\section{Tinjauan Pustaka}

\subsection{Kota Tarakan}

Menurut Theodorus Filipus Dkk (2019) menyebutkan kota merupakan kawasan pemukiman yang secara fisik ditunjukkan oleh kumpulan rumah-rumah yang mendominasi tata ruangnya dan memiliki fasilitas untuk mendukung kehidupan warganya secara mandiri. Kota tarakan memiliki letak yang strategis sebagai kota yang berkembang di wilayah Kalimantan utara, selain itu juga memiliki garis pantai dengan panjang kurang lebih $65 \mathrm{Km}$ mengelilingi pulau Tarakan (Prihartanto dkk, 2016). Daerah pesisir yang dominan dihuni oleh para nelayan sebagai aktifitas kegiatan melaut, bertani rumput laut, dan melakukan kegiatan sehari-hari lainnya.

Tabel 1 Luas Wilayah Kota Tarakan

\begin{tabular}{ccccc}
\hline \multirow{2}{*}{ No } & \multirow{2}{*}{ Kecamatan } & \multicolumn{2}{c}{ Luas Wilayah $\left.\mathbf{( m}^{\mathbf{2}}\right)$} & \multirow{2}{*}{ Total } \\
\cline { 3 - 4 } & & Daratan & Lautan & \\
\hline 1 & Tarakan Timur & 58,01 & 299,69 & 357,70 \\
2 & Tarakan Tengah & 55,54 & 28,46 & 84,00 \\
3 & Tarakan Barat & 27,89 & 18,46 & 46,35 \\
4 & Tarakan Utara & 109,36 & 59,92 & 169,28 \\
& Jumlah & $\mathbf{2 5 0 , 8 0}$ & $\mathbf{4 0 6 , 5 3}$ & $\mathbf{6 5 7 , 3 3}$ \\
\hline
\end{tabular}

Sumber: Kantor Pertanahan Kota Tarakan

Kota Tarakan mempunyai luas $657,33 \mathrm{~km} 2$ dengan dengan $38,2 \%$ wilayahnya berupa daratan dan sisanya berupa lautan dengan batas-batas sebagai berikut:

1. Sebelah Utara berbatasan dengan Pesisir pantai Kecamatan Pulau Bunyu, Kab. Bulungan

2. Sebelah Selatan berbatasan dengan Pesisir pantai Kecamatan Tanjung Palas, Kab. Bulungan 
3. Sebelah Timur berbatasan dengan Kecamatan Pulau Bunyu, Kab. Bulungan dan Laut Sulawesi

4. Sebelah Barat berbatasan dengan Pesisir pantai Kecamatan Sesayap, Kab. Bulungan

\subsection{Wilayah Pesisir}

Menurut UU Nomor 27 tahun 2007, wilayah pesisir adalah daerah peralihan antara ekosistem darat dan laut yang dipengaruhi oleh perubahan di darat dan dilaut. Kawasan pesisir mempunyai potensi pembangunan yang sangat tinggi, potensi tersebut antara lain: 1) sumber daya yang dapat di perbaharui (hutan mangrove, terumbu karang, padang lamun dan rumput laut dan sumber daya perikanan laut); 2) sumber daya yang tidak dapat di perbaharui, terdiri dari sumber daya mineral dan geologis (Kurniawati Hapsari Ekosafitri Dkk, 2017). Menurut Rustiadi (2003), secara alamiah kawasan pesisir pada dasarnya bukan semata-mata merupakan kawasan peralihan ekosistem daratan dan laut, namun sekaligus merupakan titik temu antara aktivitas ekonomi masyarakat berbasis daratan dan lautan.

\subsection{Permukiman Pesisir}

Permukiman adalah bagian dari lingkungan hidup diluar kawasan lindung, baik berupa kawasan perkotaan maupun pedesaan yang berfungsi sebagai lingkungan tempat tinggal atau lingkungan hunian dan tempat kegiatan yang mendukung perikehidupan dan penghidupan (UU No. 4 tahun 1992). Permukiman nelayan merupakan lingkungan tempat tinggal dengan prasarana dan sarana dasar yang sebagian besar penduduknya merupakan masyarakat yang memiliki pekerjaan sebagai nelayan dengan kawasan perairan sebagai tempat mereka mencari nafkah, meskipun demikian sebagian dari mereka masih tekait dengan daratan. Kawasan pemukiman nelayan haruslah memenuhi prinsip-prinsip layak huni yaitu memenuhi persyaratan teknis, persyaratan administrasi maupun persyaratan lingkungan. Dari berbagai parameter tentang permukiman dan karakteristik nelayan dapat dirumuskan bahwa permukiman nelayan merupakan suatu lingkungan masyarakat dengan sarana dan prasarana yang harusnya mendukung serta mempunyai keterkaitan dengan dengan sumber mata pencaharian mereka sebagai nelayan (Muhammad Himan Dkk, 2018).

\subsection{Masyarakat Pesisir}

Karakteristik masyarakat pesisir berbeda dengan karakteristik masyarakat agraris atau petani. Dari segi penghasilan, petani mempunyai pendapatan yang dapat dikontrol karena pola panen yang terkontrol sehingga hasil pangan atau ternak yang mereka miliki dapat ditentukan untuk mencapai hasil pendapatan yang mereka inginkan. Berbeda halnya dengan masyarakat pesisir yang mata pencahariannya didominasi dengan nelayan. nelayan begelut dengan laut untuk mendapatkan penghasilan, maka pendapatan yang mereka inginkan tidak bisa dikontrol. Nelayan menghadapi sumberdaya yang bersifat open acces dan beresiko tinggi. Hal tersebut menyebabkan masyarakat pesisir seperti nelayan memiliki karakter yang tegas, keras, dan terbuka (Rizki Aprilian Wijaya, 2012).

\subsection{Sarana dan Prasarana (Infrastruktur)}

KBBI menyatakan bahwa sarana adalah segala sesuatu yang dapat dipakai sebagai alat dalam mencapai maksud atau tujuan. Dan prasarana adalah segala sesuatu yang merupakan penunjang utama terselenggaranya suatu proses (usaha, pembangunan, proyek).

Menurut Moenir (1992-119), mengatakan sarana adalah segala jenis peralatan, perlengkapan kerja dan fasilitas yang berfungsi sebagai alat utama atau pembantu dalam pelaksanaan pekerjaan, dan juga dalam rangka kepentingan yang sedang berhubungan dengan organisasi kerja.

Dari pengertian sarana yg di katakan Moenir tersebut jelas memberi petunjuk sarana merupakan seperangkat alat yang digunakan dalam suatu proses kegiatan baik alat tersebut. Sementara 
prasarana adalah peralatan pembantu atau juga peralatan utama, dan kedua alat tersebut berfungsi untuk mewujudkan suatu tujuan yang ingin di capai. Menurut Bajar \& Rajeev (2016), komponen infrastruktur, terutama listrik dan jalan, cenderung meningkatkan kesenjangan di tingkat regional.

\subsection{Pengembangan Wilayah}

Pengembangan wilayah merupakan program yang menyeluruh dan terpadu dari semua kegiatan dengan memperhitungkan sumber daya yang ada dan kontribusinya pada pembangunan suatu wilayah (Adisasmita, 2008). Luca (2015) berpendapat pembangunan daerah juga membutuhkan peran pemerintah pusat pada era desetralisasi sekarang ini. Beberapa fakta empiris menunjukkan bahwa perkembangan kapasitas infrastruktur di suatu wilayah berjalan seiring dengan perkembangan ekonominya (Calderón \& Servén, 2014), namun demikian pembangunan infrastruktur yang tidak seimbang dapat menyebabkan kegagalan terhadap pengurangan ketimpangan pertumbuhan ekonomi (Chotia \& Rao, 2017). Selanjutnya, studi Maryaningsih et al. (2014) menemukan bahwa kondisi infrastruktur jalan dan listrik berdampak signifikan terhadap pertumbuhan pendapatan per kapita. Tetapi Prasetyo et al, (2013) menunjukkan bahwa infrastruktur memiliki hubungan tidak langsung dengan ketimpangan pendapatan melalui pendapatan per kapita. Valerio Mendoza (2017) menyatakan bahwa keberadaan infrastruktur berkaitan dengan ukuran ketimpangan pendapatan wilayah. Hasil penelitian Majumder (2012) menunjukkan bahwa infrastruktur yang memadai dapat meningkatkan standar hidup rata-rata dan menurunkan angka kemiskinan.

Menurut Nugroho dan Dahuri (2012), alasan pegelolaan wilayah pesisir dan lautan harus memenuhi kaidah berkelanjutan adalah sebagai berikut:

a) Komponen hayati dan non hayati dalam wilayah pesisir membentuk suatu ekosistem yang kompleks hasil dari ragam biofisik (ekologis) yang rentan terhadap perubahan yang disebabkan kegiatan manusia maupun bencana alam;

b) Wilayah pesisir memiliki ragam ekologi maupun keuntungan lokasi biasanya ditemukan beragam pemanfaatan untuk keperluan pembangunan seperti budidaya tambak, perikanan tangkap, pariwisata serta industry atau permukiman;

c) Wilayah pesisir pada umumnya terdapat lebih dari satu kelompok masyarakat (orang) yang mempunyai keterampilan atau keahlian kesenangan bekerja yang berbeda sebagai nelayan, petani tambak, petani rumput laut, pendamping pariwisata, serta bekerja disektor industry dan kerajinan;

d) Secara ekologis dan ekonomis, pemanfaatan pesisir secara monokultur sangat rentan terhadap perubahan internal maupun eksternal yang menjurus pada kegagalan usaha;

e) Wilayah pesisir dan laut umumnya merupakan sumber daya milik bersama yang dapat dimanfaatkan oleh semua orang.

Oleh karena itu pemanfaatan wilayah pesisir dan laut memerlukan perencanaan dan pengeloaan yang serius dari pemerintah, masyarakat, dan stakeholder yang berkepentingan didalamnya untuk menjadikan wilayah pesisir tersebut menjadi lebih berkembang.

\section{Metode Penelitian}

\subsection{Jenis Penelitian}

Penelitian ini menggunakan jenis penelitian analisis data dan kualitatif deskriptif dengan menggunakan analisis skalogram untuk mengetahui lokasi pusat pusat pertumbuhan berdasarkan ketersediaan sarana dan prasarana tiap wilayah RT yang ada di wilayah pesisir kelurahan Selumit Pantai Kota Tarakan. 


\subsection{Sumber Data Penelitian}

Data yang digunakan dalam penelitian berupa data primer yang merupakan data dari kuesioner. Kuesioner dilakukan untuk memperoleh persepsi stakeholder mengenai pengembangan kawasan pesisir di wilayah Selumit Pantai. Analisis data menggunakan metode Skalogram. Metode scalogram merupakan suatu metode analisis yang digunakan untuk mengetahui suatu daerah (dalam hal ini kelurahan) dalam rangka memberikan pelayanan kepada masyarakat. Sumber data penelitian yang digunakan oleh peneliti yakni berupa data primer dan data sekunder.

a. Data Primer

Data primer dalam penelitian ini didapat dari Observasi yaitu melalui kuesioner dan wawancara baik dengan masyarakat serta dengan pihak kelurahan Selumit Pantai.

b. Data Sekunder

Data sekunder dalam penelitian ini didapat dari studi literatur berupa jurnal-jurnal, buku teks dan data dari beberapa Instansi Pemerintahan Kota Tarakan.

\subsection{Populasi dan Sampel}

\subsubsection{Populasi/Obyek Penelitian}

Populasi menurut Sugiyono (2013:117), adalah wilayah generalisasi yang terdiri dari objek atau subjek yang mempunyai kualitas dan karakteristik tertentu yang ditetapkan oleh peneliti untuk dipelajari dan kemudian ditarik kesimpulannya. Dalam penelitian ini populasinya adalah seluruh masyarakat Kelurahan Selumit Pantai yang berjumlah sebanyak \pm 16.761 jiwa.

\subsubsection{Sampel}

Pengertian sampel menurut Sugiyono (2012:73) adalah bagian dari jumlah dan karakteristik yang dimiliki oleh populasi tersebut sampel yang diambil dari populasi tersebut harus betul-betul representative (mewakili). Ukuran sampel merupakan banyaknya sampel yang akan diambil dari suatu populasi.

\subsection{Teknik Analisis Data}

Penggunakan metode analisis kualitatif. Analisis dilakukan untuk menghitung jumlah prasarana dan sarana yang memadai serta tidak memadai dengan menggunakan metode parametrik serta menggambarkan atau menguraikan secara jelas mengenai kondisi prasarana dan sarana yang ada pada lokasi penelitian di Selumit Pantai Kota Tarakan. Desain penelitian yang dilaksanakan adalah dengan metode survei atau terjun langsung ke lokasi penelitian dengan tujuan untuk memperoleh data dan informasi yang akurat dari masyarakat maupun dari prasarana lingkungan permukiman yang ada. Prasarana dan sarana yang ada akan dinilai oleh masyarakat. hadap pertumbuhan ekonomi kabupaten. Setiap-setiap Rukun Tetangga pada Kelurahan Selumit Pantai yang terdapat di wilayah pesisir sebagai kawasan strategis merupakan sebuah tantangan bagi Pemerintah Daerah dalam menetapkan strategi perencanaan yang matang dalam mendorong pertumbuhan ekonomi wilayah. Oleh sebab itu, diperlukan suatu penelitian untuk menganalisis Prasarana dan sarana untuk mendukung perkembangan ekonomi wilayah. Hal ini sejalan dengan pendapat Morrissey dan Oe'Donoghue, (2012) bahwa analisis ekonomi wilayah penting dilakukan untuk menyediakan akses bagi pemegang kebijakan terkait dampak sektor ekonomi. Analisis juga bisa digunakan untuk kebijakan wilayah regional masa depan untuk memastikan keberlanjutan dalam memperoleh dampak sebelum dilakukan pengambilan keputusan.

\subsection{Metode Skalogram}

Analisis skalogram merupakan alat untuk mengidentifikasi pusat pertumbuhan wilayah berdasarkan fasilitas yang dimilikinya, dengan demikian dapat ditentukan hierarki pusat-pusat 
pertumbuhan dan aktivitas pelayanan Suatu wilayah (Utari,2014). Data yang dikumpulkan yaitu jumlah Prasarana dan sarana yang tersedia dalam masing - masing Rukun Tetangga (RT) di Kelurahan Selumit Pantai. Sedangkan Metode yang digunakan untuk mengumpulkan data adalah dengan metode dokumentasi yang berkaitan dengan objek penelitian. Alat analisis yang digunakan dalam penelitian adalah analisis skalogram. Analisis Skalogram pada umunya dipergunakan untuk menganalisis pusat-pusat permukiman, kususnya hirarki atau orde pusat-pusat permukiman. Analisis ini untuk memberikan gambaran adanya pengelompokkan permukiman sebagai pusat pelayanan dengan mendasarkan pada kelengkapan fungsi pelayanannya. Fasilitas yang digunakan Pada penilaian ini adalah fasilitas yang mencirikan fungsi pelayanan sosial dan ekonomi dengan kriteria obyek tunggal dan terukur serta sedapatnya memiliki karakteristik hirarki atau berjenjang. Tahapan pertama dalam analisis ini adalah memilih jenis fasilitas yang digunakan sebagai variabel dalam matriks skalogram.

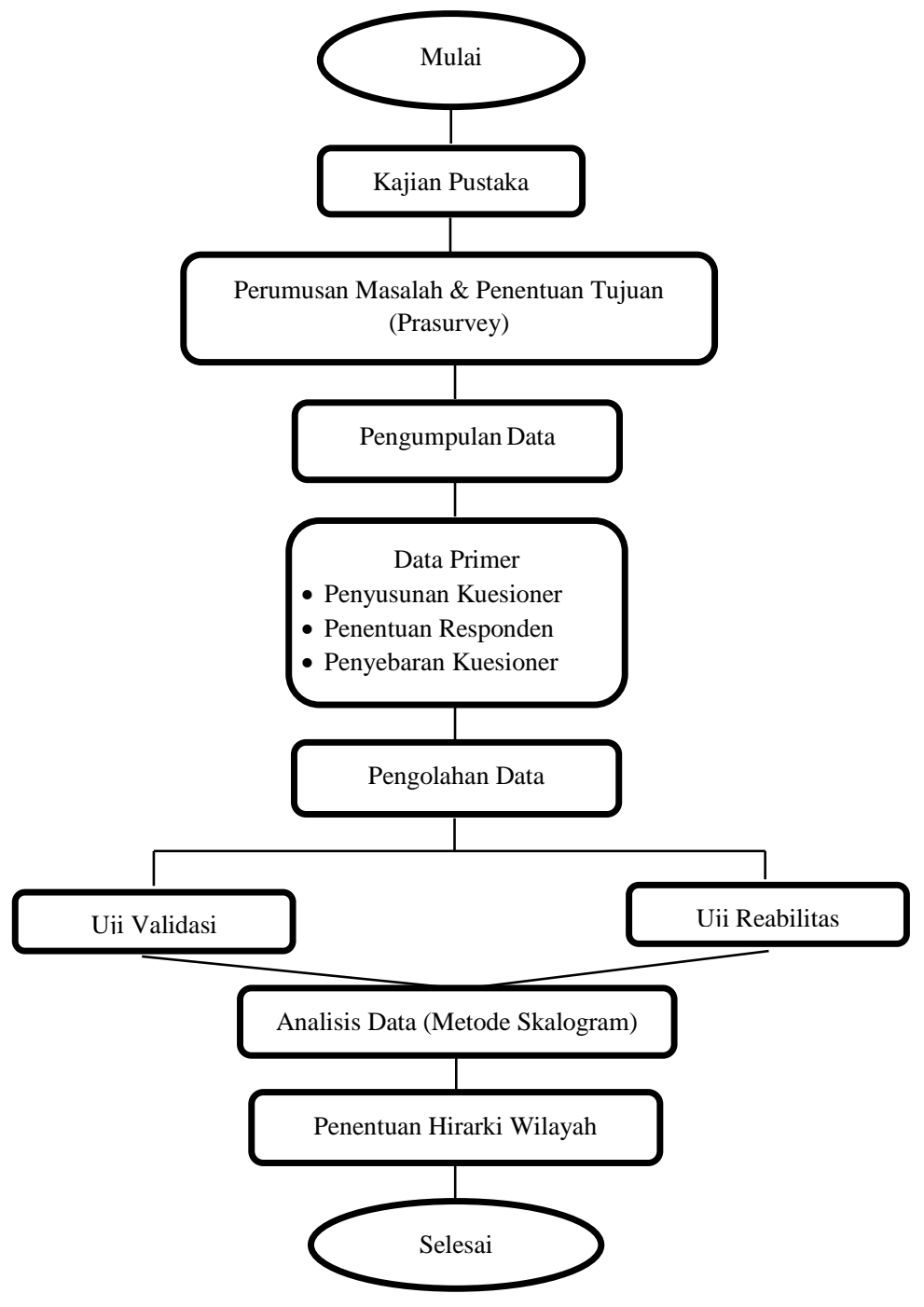

Gambar 1 diagram alir penelitian

\subsection{Penentuan Hirarki Wilayah}

Perkembangan suatu wilayah bisa dilihat salah satunya dari ketersediaan jumlah dan jenis sarana pelayanan di wilayah tersebut. Melalui pendekatan konsep wilayah nodal, dapat diketahui wilayah 
yang menjadi pusat-pusat (inti) dan wilayah yang menjadi pendukung atau hinterland (Saefulhakim, 2004). Infrastruktur atau tersedianya prasarana dan sarana dalam kaitannya dengan strategi pengembangan wilayah, perlu diidentifikasi di wilayah-wilayah yang menjadi pusat pertumbuhan yang mampu menggerakkan ekonomi wilayah di sekitarnya. Melalui pendekatan konsep wilayah nodal, dapat diketahui wilayah yang menjadi pusat-pusat (inti) dan wilayah yang menjadi pendukung (hinterland). Identifikasi terhadap wilayah inti dan hinterland penting dilakukan untuk menentukan prioritas wilayah pembangunan. Fokus pembangunan pada pusatpusat pertumbuhan yang menjadi inti wilayah akan memudahkan dalam penetapan prioritas wilayah pembangunan dimana pelaksanaan pembangunan pada wilayah inti diharapkan dapat memberikan multiplier effect terhadap perkembangan wilayah-wilayah di sekitarnya.

Kebijakan pengembangan wilayah juga dapat dilakukan melalui pengelompokan wilayah. Pengelompokan wilayah merupakan alat untuk menganalisis pengembangan wilayah berdasar keunggulan sektor di wilayah tersebut. Pengelompokan wilayah berdasarkan sektor unggulan wilayah dapat menjadi penentu kebijakan dalam pengembangan suatu wilayah (Fundeanu, 2015). Variabel lain yang digunakan dalam pengelompokan wilayah adalah kelengkapan infrastruktur. Kelengkapan infrastruktur di suatu wilayah akan membawa investasi dari luar masuk ke dalam wilayah tersebut (Alecsandru dan Raluca, 2015). Adapun alur penelitian yang digunakan dapat dilihat pada gambar 1.

\section{Hasil dan Pembahasan}

\subsection{Penentuan Jumlah Responden.}

Dalam menentukan jumlah responden menggunakan rumus Slovin. Rumus Slovin adalah suatu system matematis yang digunakan untuk menghitung jumlah dari sebuah populasi objek tertentu yang belum diketahui karakteristiknya secara pasti.

Rumus Slovin :

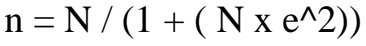

Dimana :

$\mathrm{n}=$ number of sample (jumlah sample)

$\mathrm{N}=$ total population (jumlah seluruh anggota populasi)

$\mathrm{e}=$ error tolerance ( toleransi terjadinya galat)

Untuk jumlah warga dalam kelurahan Selumit Pantai berjumlah \pm 16.761 jiwa. Kemudian kami mengambil nilai error tolerance (e) adalah $10 \%$.

Sehingga diperoleh :

$\mathrm{n}=\mathrm{N} /\left(1+\left(\mathrm{N} \mathrm{x} \mathrm{e}^{\wedge} 2\right)\right)$

$\mathrm{n}=16.761 /(1+(16.761 \times \llbracket 10 \% \rrbracket \wedge 2))$

$\mathrm{n}=99,4069 \approx 100$

Jadi, dari rumus didapat jumlah responden yaitu 100 jiwa.

\subsection{Metode Analisis}

Analisis data kami menggunakan metode Skalogram. Metode scalogram merupakan suatu metode analisis yang digunakan untuk mengetahui suatu daerah (dalam hal ini kelurahan) dalam rangka memberikan pelayanan kepada masyarakat. 
Analisis Skalogram digunakan untuk melihat gambaran tingkat perkembangan suatu wilayah secara administratif dengan menggunakan kelengkapan sarana dan prasarana (infrastruktur) di wilayah tersebut. Wilayah yang menjadi objek penelitian ini adalah RT. 17, 18, 19, 21, dan 28di Kelurahan Selumit Pantai. Analisis Skalogram untuk melihat tingkat perkembangan wilayah digunakan dalam penelitian Syafi'I dan Santoso (2015), Utari (2015) dan Sadik (2016).

Tahapan pertama dari analisis ini adalah memilih jenis fsilitas yang digunakan sebagai variable dalam matriks Skalogram. Dari hasil observasi yang telah dilakukan terdapat beberapa sarana dan prasarana (infrastruktur) yang ada di wilayah Selumit Pantai yaitu :

\section{Jalan}

Keberadaan prasarana jalan di wilayah Selumit Pantai sangat mempengaruhi pergerakan orang dan barang baik kedalam maupun keluar masuk wilayah tersebut.. Selain itu, keberadaan prasarana jalan tersebut juga akan berpengaruh terhadap pertumbuhan ekonomi wilayah setempat. Prasarana jalan ini sendiri terdapat disetiap daerah di wilayah Selumit pantai terutama di RT yang kami tinjau yaitu RT 17, 18, 19, 21 dan 28. Akan tetapi akses jalan di daerah ini kurang atau tidak melayani seluruh lingkungan permukiman karena masih ada beberapa akses jalan yang belum diaspal masih berupa jalan berbentuk kayu sehingga perlu adanya peningkatan jalan atau pengaspalan jalan, kemudian akses jalan di daerah ini juga masih sempit sehingga terkadang menghambat aktivitas untuk bepergian apalagi didaerah ini aktivitas kegiatannya sangat padat.

\section{Lampu penerangan jalan}

Lampu penerangan jalan yang ada di wilayah Selumit Pantai cukup memadai karena dengan adanya lampu penerangan jalan dapat meningkatkan keamanan, keselamatan, dan kemudahan masyarakat dalam beraktivitas di malam hari. Sehingga dapat meningkatkan taraf hidup baik secara sosial maupun ekonomi. Lampu penerangan jalan ini sendiri terdapat di semua RT begitu pula dengan RT yang kami tinjau RT 17, 18, 19, 21, dan 28 akan tetapi tidak terlalu banyak terkadang penerangan juga di bantu oleh lampu rumah warga sekitar karena biasanya lampu penerangan jalan ini hanya ada di sudut sudut jalan. Penerangan jalan umum memang menjadi kebutuhan yang sangat diharapkan masyarakat khususnya di daerah pesisir seperti wilayah Selumit Pantai.

\section{Pasar}

Berkembangnya pembangunan disuatu wilayah ditentukan oleh tingkat perekonomian penduduk wilayah pesisir tersebut, oleh karena itu fasilitas perdagangan seperti pasar sangat diperlukan agar dapat menunjang pembangunan wilayah ini akan tetapi pasar ini tidak tersedia di beberapa RT yang kami tinjau. Pasar yang ada di wilayah Selumit Pantai juga memudahkan warganya dalam rangka pemenuhan kebutuhan primer dan sekunder selai itu juga pasar ini mudah diakses karena letak pasar berada di jalan masuk Selumit Pantai, kondisi pasar nya juga cukup baik..Pasar juga bisa menjadi tempat bagi masyarakat untuk mencari uang sebagai sumber mata pencaharian sehingga dapat menjadi sebuah media yang bisa meningkatkan perekonomian penduduk. Dengan adanya pasar ini , maka tingkat kesejahteraan masyarakat wilayah pesisir Selumit Pantai dapat meningkat. Akan tetapi tidak semua barang yang dibutuhkan masyarakat Selumit Pantai tersedia, sehingga biasanya masyarakat yang tidak mendapatkan barang yang diinginkannya akan mencari ke pasar yang lebih lengkap.

\section{Masjid}

Masjid sangat berguna dan bermanfaat di Selumit Pantai karena dengan adanya masjid ini sendiri dapat mempermudah masyarakat untuk beribadah, sehingga masyarakat wilayah pesisir dapat menjadikan masjid sebagai pusat kegiatan agama, landasan pembentukan umat, lambang syiar Islam, dan basis perjuangan dan dakwah untuk menegakkan keadilan dan kebenaran. dapat menjadikan sumber daya manusia yang berkualitas sebagai modal pembangunan yang sangat 
penting. Masjid yang ada diwilayah Selumit Pantai ada 2, akan tetapi hanya 1 masjid yang terdapat di RT yang kami tinjau yaitu di RT 17.

\section{PAUD}

Di wilayah Selumit Pantai juga terdapat PAUD tetapi fasilitas ini belum ada di RT yang kami tinjau, sehingga orang tua yang ingin anaknya memiliki pendidikan anak usia dini bisa disekolahkan di PAUD tersebut yang tidak perlu jauh keluar ke daerah yang ada PAUD nya juga. Dengan adanya PAUD ini juga membantu anak-anak wilayah pesisir memiliki pengetahuan sebelum masuk ke jenjang sekolah yang lebih tinggi.

\section{SD (Sekolah Dasar)}

Pendidikan merupakan salah satu usaha dalam rangka meningkatkan kehidupan intelektual Bangsa yang pada akhirnya akan membentuk kepribadian dan kemampuan di dalam dan di luar sekolah serta berlangsung seumur hidup. Di wilayah Selumit Pantai ini hanya terdapat Sekolah Dasar ( SD ) itupun fasilitas ini tidak ada di beberapa RT yang kami tinjau. Sehingga jika anak-anak yang tinggal wilayah pesisir ini ingin melanjutkan SMP dan SMA bisa melanjutkan di daerah yang terdapat jenjang sekolah lebih tinggi. Akan tetapi jika dilihat dari tingkat pendidikan sudah bisa dikatakan cukup baik karena rata-rata anak anak banyak yang bersekolah walaupun bukan sekolah di wilayah tersebut.

\section{Fasilitas kesehatan (klinik)}

Masyarakat pesisir termasuk nelayan memiliki risiko kesehatan yang tinggi sehingga perlu diberikan perhatian khusus dalam upaya pembangunan kesehatan Fasilitas kesehatan di Kelurahan Selumit Pantai cukup memadai, dengan adanya Praktek kesehatan dan apotek. Pada umumnya masyarakat telah memanfaatkan keberadaan fasilitas Kesehatan tersebut, namun biasanya masyarakat lebih sering berobat di Puskesmas yang terdapat dengan asumsi ketersediaan tenaga medis dan alat medis lebih lengkap. Fasilitas kesehatan ini ada dibeberapa RT yang kami tinjau yaitu RT 19 dan 21.

\section{Tempat wisata}

Kelurahan Selumit Pantai juga memiliki satu-satunya obyek wisata seperti Tempat wisata yang bernama Taman Barokah berada pada RT 17 yang menjadi simbol kebanggaan destinasi wisata yang telah mengambil langkah tepat dalam mengembangkan daerah Selumit Pantai sendiri sesuai dengan potensi yang dimilikinya. Dengan kondisi tersebut maka kawasan pesisir Selumit Pantai terus mengalami perbaikan dan peningkatan kualitas dengan di bangunnya tempat wisata yang ada di sekitar pantai yang didukung oleh sarana pelengkap seperti gazebo. Menurut Harry Robinson (1976), dalam pengembangan kawasan wisata minimal memiliki 3 faktor penunjang, antara lain objek wisata yang ditawarkan, sarana dan prasarana penunjang, dan peran serta masyarakat. Akan tetapi tempat wisata belum diketahui oleh orang banyak, maka dari itu pemerintah kota Tarakan seharusnya mempromosikan adanya taman wisata ini yang dapat meningkatkan kemajuan itu sendiri untuk wilayah Selumit pantai.

\section{Profil air}

Di wilayah pesisir Selumit Pantai juga terdapat profil bak air yang hanya tersedia di RT 18, berguna untuk membantu jika ada kebakaran, profil bak air ini sendiri sangat bermanfaat bagi para warga yang ada di wilayah pesisir, karena jika terjadi kebakaran dapat memudahkan untuk mendapatkan air. Ditambah dengan akses yang susah atau jalan yang sempit sehingga jika terjadi kebakaran mobil pemadam kebakaran sulit untuk masuk ke daerah tersebut. 


\section{Bak air pembuangan}

Bak air pembuangan di wilayah pesisir ini menampung kotoran dari berbagai rumah warga dengan pipa-pipa penyaluran sebelum dilakukan pembuangan ke laut, akan tetapi tidak semua rumah warga terdapat pipa penyaluran sehingga kotoran yang ada biasanya langsung dibuang ke laut dan terbawa oleh arus. Bak air ini juga hanya terdapat pada RT 18

\section{Pabrik es}

Pabrik es merupakan sarana yang berfungsi untuk kebutuhan es, agar dapat mempertahankan mutu produksi selama proses panen dan didistribusikan. Kondisi pabrik es yang ada di wilayah Selumit Pantai cukup memadai yang tersedia di RT 18 dan Rt 28. Pabrik es ini sangat bermanfaat untuk para nelayan agar tidak terhambat dalam mengelola hasil perikanan, dengan adanya pabrik es didaerah ini juga nelayan tidak akan lagi sering risau sebab ikan tidak cepat membusuk dan dapat meningkatkan hasil tangkapan yang akan mendorong kemajuan perekonomian daerah Selumit Pantai.

\section{Posyandu balita}

Posyandu sebenarnya sangat penting dan bermanfaat, namun kurang berjalan lancar. Maka perlu ditingkatkan pemberdayaan masyarakat untuk memberikan pelayanan kesehatan bayi atau balita, ibu hamil atau ibu menyusui. Program posyandu di wilayah Selumit Pantai menjadi garda terdepan untuk meningkatkan kesehatan masyarakat. Posyandu balita yang ada di Selumit Pantai ini tidak di semua Rt ada akan tetapi di RT yang kami tinjau seperti 18 dan 19 ada fasilitas tersebut, terkadang juga hanya memiliki beberapa bangunan posyandu yang digunakan untuk gabungan beberapa Rt, kondisi posyandu ini cukup memadai tetapi perlu pembangunan lanjutan agar lebih layak digunakan oleh masyarakat Selumit Pantai.

\section{Posyandu lansia}

Posyandu Lansia sangat penting dan berguna bagi warga pesisir Selumit Pantai yang lanjut usia untuk mendapatkan pelayanan agar dapat memeriksa kesehatan mereka secara berkala. Posyandu lansia ini juga seperti posyandu balita yang tidak semua RT terdapat posyandu tersebut, salah satunya ada di RT 18.

\section{TPA (Tempat Pendidikan Agama)}

TPA merupakan sebuah lembaga pendidikan yang bertujuan untuk membentuk karakter anak-anak menjadi lebih mandiri dan berakhlak. TPA ini sangat bermanfaat bagi anak-anak diwilayah pesisir yang ingin memperdalam agamanya, sehingga para orang tua tidak perlu khawatir anak-anaknya mengalami kemerosotan akhlak remaja yang mana disebabkan oleh perkembangan ilmu pengetahuan dan teknologi yang semakin canggih. Karena di TPA ini akan diajarkan belajar ilmu agama dan juga ilmu yang bersifat umum dan di didik bagaimana hidup mandiri. TPA ini hanya ada 1 di wilayah Selumit Pantai yang ada di RT 18

\section{TPI (Tempat Pelelangan Ikan)}

Untuk mendukung kegiatan perikanan di Kelurahan Selumit Pantai maka dibangun Tempat Pelelangan Ikan (TPI) yang lebih tepatnya berada RT 28. Tempat Pelelangan Ikan (TPI) sama halnya dengan kegiatan industri yang membutuhkan infrastruktur dengan kualitas tinggi. Karena infrastruktur sangat berperan dalam aktivitas di Tempat Pelabuhan Perikanan (TPI). Keberadaan Tempat Pelelangah Ikan (TPI) dapat membawa dampak positif dalam peningkatan pembangunan infrastruktur yang pastinya juga akan berimbas pada peningkatan sosial dan ekonomi masyarakat setempat Selumit Pantai. Terlebih dengan keberadaan Tempat Pelelangan Ikan (TPI) yang di mana menarik bangkitan kegiatan di Kelurahan Selumit Pantai yang tentu saja membutuhkan ketersediaan infrastruktur yang memadai. 


\section{PDAM}

Masyarakat wilayah Selumit Pantai memenuhi kebutuhan air bersih menggunakan PDAM secara perorangan fasilitas ini sendiri juga tersedia di RT yang kami tinjau. Untuk wilayah pesisir di Kelurahan Selumit Pantai terkadang menggunakan air hujan jika air PDAM tidak dapat digunakan atau biasanya mati . Akan tetapi sebagian masyarakat Selumit Pantai ada yang belum mendapatkan penyediaan air bersih seperti PDAM, sehingga masyarakat yang tidak kebagian penyedian air bersih hanya memanfaatkan air hujan.

Tabel 2. Fasilitas Di Kelurahan Selumit Pantai

\begin{tabular}{|c|c|c|c|c|c|c|c|c|c|c|c|c|c|c|c|c|c|c|}
\hline \multirow[b]{2}{*}{$\dot{\mathbf{Z}}$} & \multirow[b]{2}{*}{ ๘ } & \multicolumn{16}{|c|}{ Fasilitas } & \multirow[b]{2}{*}{ 节 } \\
\hline & & $\frac{\Xi}{\frac{\Xi}{\Xi}}$ & 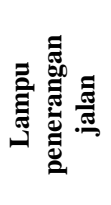 & $\sum_{2}$ & 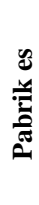 & 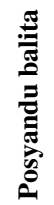 & 䓀 & 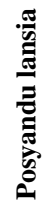 & 苛 & 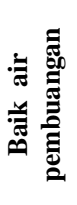 & 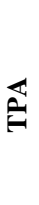 & 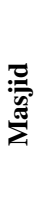 & 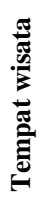 & $\bar{E}$ & تَّ & \% & 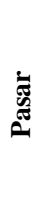 & \\
\hline 2. & 18 & 1 & 2 & 1 & 1 & 1 & 0 & 1 & 9 & 2 & 1 & 0 & 0 & 0 & 0 & 0 & 0 & 19 \\
\hline 3. & 19 & 1 & 3 & 1 & 0 & 1 & 1 & 0 & 0 & 0 & 0 & 0 & 0 & 0 & 0 & 0 & 0 & 7 \\
\hline 4. & 21 & 1 & 4 & 1 & 1 & 0 & 1 & 0 & 0 & 0 & 0 & 0 & 0 & 0 & 0 & 0 & 0 & 8 \\
\hline 5. & 28 & 1 & 2 & 1 & 1 & 0 & 0 & 0 & 0 & 0 & 0 & 0 & 0 & 5 & 0 & 0 & 0 & 10 \\
\hline \multicolumn{2}{|c|}{ Jumlah } & 5 & 12 & 5 & 3 & 2 & 2 & 1 & 9 & 2 & 1 & 1 & 1 & 5 & 0 & 0 & 0 & 49 \\
\hline
\end{tabular}

Pada tabel diatas terdapat 16 fasilitas. Untuk RT yang memiliki jumlah fasilitas tertinggi adalah RT. 18 dengan jumlah 19 fasilitas dan RT yang memiliki fasilitas terendah adalah RT.17 dengan jumlah 5 fasilitas. Tahap selanjutnya dari analisis skalogram adalah mengkonversi seluruh fasilitas yang ada kedalam angka (1) dan fasilitas yang tidak ada (0).

Tabel 3. Data Perhitungan Skalogram

\begin{tabular}{|c|c|c|c|c|c|c|c|c|c|c|c|c|c|c|c|c|c|c|c|}
\hline No & RT & \multicolumn{16}{|c|}{ Fasilitas } & 売 & 章 \\
\hline 2. & 18 & 1 & 1 & 1 & 1 & 1 & 0 & 1 & 1 & 1 & 1 & 0 & 0 & 0 & 0 & 0 & 0 & 9 & 2 \\
\hline 3. & 19 & 1 & 1 & 1 & 0 & 1 & 1 & 0 & 0 & 0 & 0 & 0 & 0 & 0 & 0 & 0 & 0 & 5 & 2 \\
\hline 4. & 21 & 1 & 1 & 1 & 1 & 0 & 1 & 0 & 0 & 0 & 0 & 0 & 0 & 0 & 0 & 0 & 0 & 5 & 2 \\
\hline
\end{tabular}

Keterangan :

F1 = Jalan; F2= Lampu penerangan jalan; F3= PDAM; F4= Pabrik es; F5= Posyandu balita; F6= Klinik; F7= Posyandu lansia; F8= Profil air; F9= Bak air pembuangan; F10 = Taman Pendidikan Alquran; F11= Masjid; F12= Tempat wisata; F13= Tempat Pelelangan Ikan; F14= Pendidikan Anak Usia Dini; F15= Sekolah Dasar; F16= Pasar.

Setelah data diurutkan sesuai dengan kelengkapan fasilitasnya didapatkan jumlah error totalnya sebanyak 8, dan jumlah total fasilitas yang tersedia adalah sebnyak 29 dengan jumlah terbesar adalah 19 dan jumlah terkecil adalah 5 fasilitas. Dari data-data tersebut,dapat dilakukan analisis skalogram berdasarkan Teori Guttman.

Tahapan selanjutnya adalah menetukan jumlah hirarki yaitu

Jumlah Hirarki $=1+3,3 \log n$

Dimana :

$\mathrm{n}=$ Jumlah RT

Perhitungan

Jumlah Hirarki $=1+3,3 \log \mathrm{n}$

$$
\begin{aligned}
& =1+3,3 \log 5 \\
& =1+3,3(0,699)
\end{aligned}
$$




$$
\begin{aligned}
& =1+2,3067 \\
& =3,3067 \\
& =3
\end{aligned}
$$

Sebelum menentukan hirarki, perlu diketahui Range untuk masing-masing hirarki. Perhitungan Range hirarki dilakukan dengan cara :

Range $=($ nilai tertinggi - nilai terendah $) /$ jumlah hirarki

$$
\begin{aligned}
& =(19-5) / 3 \\
& =4,67
\end{aligned}
$$

\begin{tabular}{lc} 
Tabel 4. Range Hirarki \\
\hline Hirarki I & $>14,34-19$ \\
Hirarki II & $9,67-14,33$ \\
Hirarki III & $5-9,66$ \\
\hline
\end{tabular}

Tabel 5. Hasil Analisis Hirarki Perkembangan Wilayah Keluaran Selumit Pantai

\begin{tabular}{ccccc}
\hline No & RT & Jumlah Fasilitas & Error & Hirarki \\
\hline 1. & 17 & 5 & 4 & Hirarki III \\
2. & 18 & 9 & 2 & Hirarki III \\
3. & 19 & 5 & 2 & Hirarki III \\
4. & 21 & 5 & 2 & Hirarki III \\
5. & 28 & 5 & 2 & Hirarki III \\
\hline
\end{tabular}

Hasil analisis menggunakan metode skalogram ini dengan mendapatkan jumlah hirarki sebanyak 3. Kelurahan Selumit Pantai ini hanya mendapatkan tingkat perkembangan yang rendah ( Hirarki 3 ) yaitu pada seluruh RT yang kami tinjau seperti RT 17, 18, 19, 21 dan 28.

Tahap terakhir dari analisis Skalogram adalah tingkat perhitungan tingkat kesalahan yang biasa disebut COR (Coeffecient Of Redductbility) dengan rumus :

$\mathrm{COR}=1-\left(\sum e\right) / \mathrm{NxK}$

Keterangan :

$\mathrm{e}=$ jumlah kesalahan

$\mathrm{N}=$ jumlah subjek/kota/RT

$\mathrm{K}=$ jumlah obyek/fasilitas

Dalam hal ini koefesien dianggap layak apabila bernilai 0,9-1. Perhitungan COR Kelurahan Selumit Pantai adalah sebagai berikut:

$\mathrm{COR}=1-\left(\sum e\right) / \mathrm{N} \times \mathrm{K}$

$\mathrm{COR}=1-(8) / 5 \times 16$

$\mathrm{COR}=1-(8) / 80$

$\mathrm{COR}=1-0,1$

$\mathrm{COR}=0,9$

Sehingga tingkat kesalahan analisis Skalogram diatas adalah 0,9 yang menunjukkan bahwa analisis Skalogram Kelurahan Selumit Pantai dianggap sudah layak. 


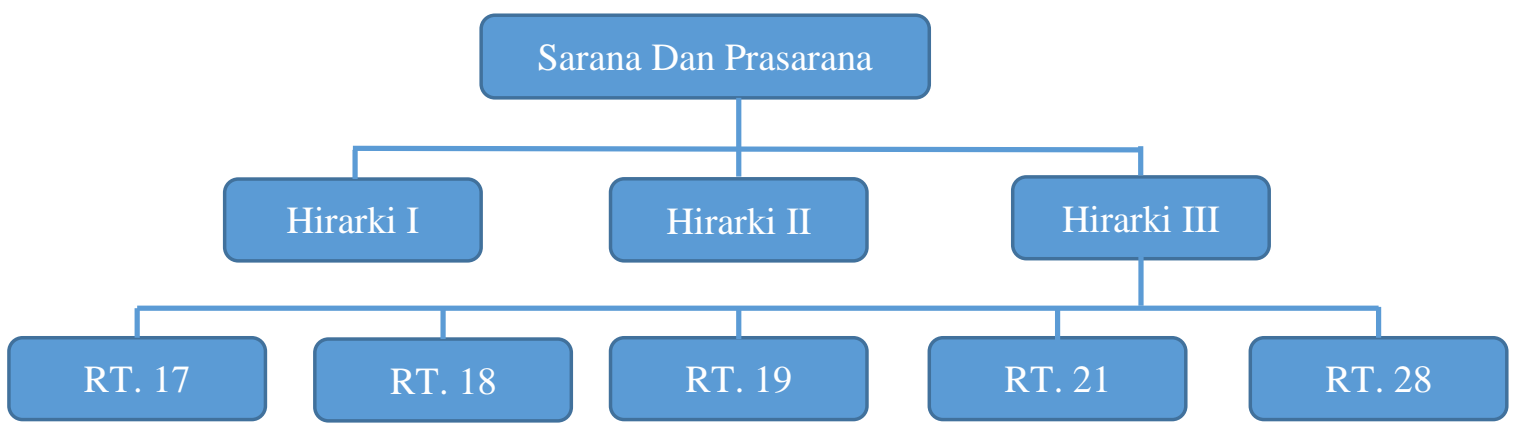

Gambar 2. Pengembangan kawasan pesisir wilayah selumit pantai berdasarkan sarana \& prasarana

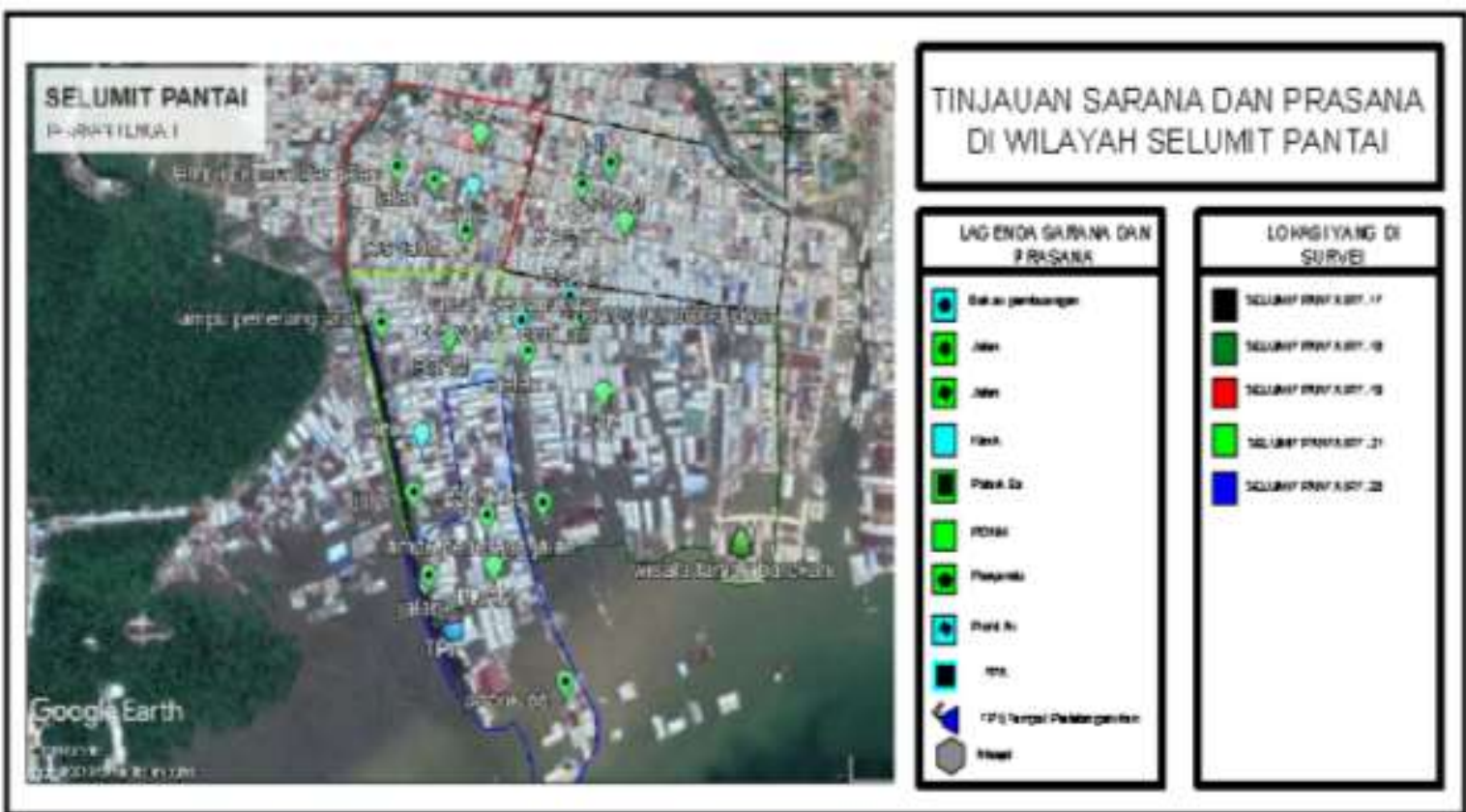

Gambar 3. Arahan pengembangan Kawasan Pesisir Kelurahan Selumit Pantai

\section{Kesimpulan}

Terdapat tiga hirarki di Kelurahan Selumit Pantai berdasarkan analisis skalogram dimana RT yang ditinjau yaitu RT 17, 18, 19, 21, dan 28 mencakup ke hirarki 3 dengan pengembangan wilayah yang rendah, Sarana dan Prasarana yang terdapat di Wilayah Selumit Pantai yaitu Jalan, lampu penerangan jalan,pasar, masjid, PAUD, SD (sekolah dasar), fasilitas kesehatan (klinik), tempat wisata, profil air, bak air pembuangan, pabrik es, posyandu balita, posyandu lansia, TPA (tempat Pendidikan agma), TPI ( tempat pelelangan ikan) dan PDAM.

\section{Daftar Pustaka}

Adisasmita, R. (2008). Pengembangan Wilayah:Konsep dan Teori. Yogyakarta: Graha Ilmu.

Bajar, S., \& Rajeev, M. (2016). The impact of infrastructure provisioning on inequality in India: Does the level of development matter? Journal of Comparative Asian Development, 15(1), 122-155. doi:10.1080/15339114.2016.1150188. 
Calderón, C., \& Servén, L. (2014). Infrastructure, growth, and inequality: An overview (Policy Research Working Paper No. 7034). Retrieved from https://openknowledge.worldbank.org/handle/10986/20365.

Chotia, V., \& Rao, N. V. . (2017). Investigating the interlinkages between infrastructure development, poverty and rural-urban income inequality: Evidence from Brics Nations. Studies in Economics and Finance, 34(4), 466-484. doi:10.1108/SEF-07-2016-0159.

Julianto, H. and Jumario, N. (2017). Pengaruh Pembangunan Infrastruktur Jalan Terhadap Penataan Kawasan Kumuh Pesisir Kota Tarakan. Jurnal Sipil Politeknik, 19(2) ,65-73.

Kurniawati H.E., Ernan R., Fredinan Y. (2017). Development of Central Java's Nothern Coast Based on Local Infrastructure: Case Study of Jepara Regency, Journal of Regional and Rural Development Planning, 1 (2), 145-157.

Luca, D. (2015). Votes and Regional Economic Growth: Evidence From Turkey. World Development. Eng., 28, 477-495.

Majumder, R. (2012). Removing poverty and inequality in India: The role of infrastructure (MPRA Paper No.40941). Munich Personal RePEc Archive. Retrieved from https://mpra.ub.unimuenchen.de/40941/1/rm24.pdf.

Maryaningsih, N., Hermansyah, O., \& Savitri, M. (2014). Pengaruh infrastruktur terhadap pertumbuhan ekonomi IndonesIa. Buletin Ekonomi Moneter Dan Perbankan, 17(1), 61-98. doi:10.21098/bemp.v17i1.44.

Muhamad Himan., Muh. Syarif., Manat Rahim. (2018). Analisis Ketersediaan Prasarana dan Sarana Permukiman Nelayan di Kelurahan Lakologou Kecamatan Kokalukuna Kota Baubau, ISSN 2502-4205, 3 (2), 1-15

Prasetyo, B. A., Priyarsono, D. S., \& Mulatsih, S. (2013). Infrastructure, economic growth and inequality in Indonesia Land Borders. Economic Journal of Emerging Markets, 5(2), 99-108. doi:10.20885/ejem.vol5.iss2.art3

Prihartanto, E. and Roem, M. (2016) 'Kajian Potensi Peningkatan Permukiman Di Kawasan Pesisir Dampak Abrasi Dengan Pemanfaatan Inderaja (Studi kasus : Pantai wisata Binalatung, Kota Tarakan)', Jurnal Harpodon, 9(2).

Rizki Aprilian W. (2012). Sebuah Pengantar Diskusi Persiapan Ekspedisi Zooxanthellae XII Kabupaten Sambas, Kalimntan Barat Tahun 2012. Balai Besar Penelitian Sosial Ekonomi Kelautan Dan Perikanan (BBPSEKP), Badan Penelitian dan Pengembangan Kelautan Dan Perikanan (Balitbang-KP).

Rustiadi, E. (2003). Pengembangan wilayah Pesisir sebagai Kawasan Strategis Pembangunan Daerah. Makalah Pelatihan Pengelolaan dan Perencanaan Wilayah Pesisir Secara Berkelanjutan. Kerjasama PKSPL IPB dengan Departemen Kelautan Dan Perikanan RI. Bogor.

Theodorus F., Linda T., Michael M.R. (2019). Analisis Struktur Ruang Berdasarkan Pusat Pelayanan Di Kabupaten Minahasa Utara, ISSN 2442-3262, 6 (1), 14-23.

Valerio Mendoza, O. (2017). Infrastructure development, income inequality and urban sustainability in the People's Republic of China (ADBI Working Paper 713). Tokyo. 